
menta dedo de moça Capsicum baccatum var. pendulum. Horticultura Brasileira 33: 324-331. DOI: http://dx.doi.org/10.1590/S0102-053620150000300008

\title{
Determinação da maturidade fisiológica de sementes de pimenta dedo de moça Capsicum baccatum var. pendulum
}

Elaine V Justino ${ }^{1}$; Leonardo S Boiteux ${ }^{2}$; Maria EN Fonseca ${ }^{2}$; José G Silva Filho²; Warley M Nascimento ${ }^{2}$

${ }^{1}$ Universidade de Brasília, Brasília-DF, Brasil; elainevazjustino@hotmail.com; ²Embrapa Hortaliças, Brasília-DF, Brasil; leonardo. boiteux@embrapa.br; maria.boiteux@embrapa.br; jose-getulio.silva@embrapa.br; warley.nascimento@embrapa.br

\section{RESUMO}

Um aspecto ainda pouco estudado, mas de grande relevância no processo produtivo de sementes de pimenta do tipo dedo de moça (Capsicum baccatum var. pendulum) é a determinação tanto da maturidade fisiológica quanto do momento mais adequado para a colheita. Neste contexto, o objetivo deste trabalho foi avaliar a qualidade fisiológica de sementes de pimenta da espécie C. baccatum var. pendulum obtidas de frutos em diferentes estádios de maturação. O experimento foi realizado nas instalações do campo experimental e laboratórios de sementes e de pós-colheita da Embrapa Hortaliças, Brasília-DF. Para a determinação da maturidade fisiológica foi utilizada a cultivar BRS Mari. As sementes foram obtidas de frutos colhidos em diferentes estádios de maturação $(20,30,40,50,60,70$ e 80 dias após antese). Foram determinados a coloração dos frutos, comprimento longitudinal, teor de clorofila e de capsaicina. Nas sementes, foram determinados o teor de água, a massa de 100 sementes, a germinação, a emergência de plântulas em casa de vegetação e o vigor, estimado pela primeira contagem de germinação e teste de envelhecimento acelerado. Foi utilizado o delineamento inteiramente casualizado. A maturidade fisiológica das sementes ocorreu aos 70 dias após a antese, onde os frutos apresentavam coloração vermelha, teores mínimos de clorofila e maiores picos de capsaicina. Neste estádio, as sementes apresentam valores máximos de germinação, vigor e matéria seca e teor de água de $39 \%$.

Palavras-chave: capsaicina, qualidade fisiológica de sementes, vigor, colheita.

\begin{abstract}
Physiological maturity determination of 'dedo de moça' hot pepper (Capsicum baccatum var. pendulum) seeds

The determination of the physiological seed maturity as well as the most appropriate harvest time are important aspects to achieve high quality seeds. This information is still not available for seed production of "dedo de moça" pepper (Capsicum baccatum var. pendulum) accessions. Thus, the objective of the present study was to evaluate the physiological seed quality of C. baccatum var. pendulum $\mathrm{cv}$. BRS Mari from fruits harvested in different physiological maturity stages. The experiment was carried out at the experimental field and laboratories at Embrapa Hortaliças, in Brasília, Brazil. Seeds were obtained from fruits harvested at different maturation stages (20, $30,40,50,60,70$ and 80 days after anthesis). We determined fruit color, length, chlorophyll and capsaicin contents, seed moisture content, 100 seed weight, germination, seedling emergence under greenhouse conditions and accelerated aging test. A completely randomized design (CRD) was used in this study. Physiological seed maturity of 'BRS Mari' occurred at 70 days after anthesis when fruits presented red color, lower chlorophyll content and highest capsaicin accumulation. At this stage, seed moisture content was 39\% and the seed mass, germination and vigor were the highest.
\end{abstract}

Keywords: C. baccatum var. pendulum, capsaicin, seed physiological quality, vigor, harvest.

(Recebido para publicação em 2 de outubro de 2014; aceito em 20 de março de 2015) (Received on October 2, 2014; accepted on March 20, 2015)

$\mathrm{O}$ mercado de sementes de hortaliças no Brasil é expressivo e altamente competitivo, com mais de 25 empresas atuando nas diversas espécies. No entanto, pouca atenção tem sido dada ao segmento de pimentas dedo de moça $(C$. baccatum var. pendulum) (Carvalho et al., 2009). A limitação da oferta de sementes de qualidade e de certo desinteresse por parte das empresas produtoras de sementes pelo desenvolvimento de novas cultivares de $C$. baccatum var. pendulum estão relacionados às deficiências nas técnicas de produção, baixo rendimento, dificuldade de extração das sementes e aos problemas relacionados com a qualidade fisiológica (Nascimento et al., 2006).

A exigência do mercado por sementes de alta qualidade leva as empresas de sementes a darem ênfase e prioridade à produção de sementes com boas características físicas, fisiológicas, genéticas, e sanitárias, além de destinarem grandes investimentos para as pesquisas nessa área (Nascimento, 2004). A utilização de sementes de qualidade comprovada traz vantagens econômicas, sociais e ambientais para os produtores e consumidores.

Os componentes relacionados com a qualidade das sementes apresentam importância equivalente. Porém, os aspectos fisiológicos têm recebido maior atenção. A alta qualidade das sementes resulta em maior vigor, emergência, uni- 
formidade e produtividade final, constituindo, portanto, fator básico para o sucesso da lavoura (Freitas et al., 2008). Em geral, para espécies cujas sementes estão contidas em frutos carnosos, como é o caso das pimentas da espécie $C$. baccatum var. pendulum, a máxima germinação e o máximo vigor geralmente ocorrem quando a semente apresenta o máximo conteúdo de matéria seca (Nascimento et al., 2006), embora, em algumas situações, estes parâmetros podem ser não coincidentes. A partir da maturidade fisiológica iniciam-se, nas sementes, alterações degenerativas que comprometem a germinação e o vigor (Carvalho \& Nakagawa, 2000). Os principais parâmetros utilizados na identificação da maturidade fisiológica das sementes em populações de plantas, bem como, o ponto ideal para a colheita, têm sido a idade e a coloração dos frutos. Essa alteração de coloração pode ser um indicativo do ponto de maturidade fisiológica das sementes, onde, geralmente, são observados níveis máximos de germinação e vigor e mínimos de deterioração (Nascimento et al., 2006). Assim, o reconhecimento prático da maturidade fisiológica geralmente é estratégico para a definição do momento ideal de colheita, contribuindo para a produção de sementes de alta qualidade fisiológica e sanitária.

Diante da demanda por pimentas do grupo varietal dedo de moça e, consequentemente, por sementes de qualidade, são necessários estudos mais aprofundados sobre os aspectos fisiológicos relacionados com o desenvolvimento, maturação e germinação das sementes de acessos de C. baccatum var. pendulum. Tais conhecimentos são imprescindíveis, principalmente, no que diz respeito ao planejamento e definição da época ideal de colheita para minimizar os efeitos da deterioração das sementes provocados pela permanência prolongada dos frutos no campo. Por outro lado, a colheita precoce dos frutos poderá acarretar grande proporção de sementes imaturas, reduzindo assim a produtividade e a qualidade das sementes (Nascimento, 2004). Desta forma, o objetivo deste trabalho foi avaliar a qualidade fisiológica de sementes de pimenta da espécie $C$. baccatum var. pendulum obtidas de frutos em diferentes estádios de maturação.

\section{MATERIAL E MÉTODOS}

O campo de produção de sementes foi instalado na área experimental da Embrapa Hortaliças, Brasília-DF (15'55'45'S, 48 08'33''O, altitude de $998 \mathrm{~m}$ ), de março a novembro de 2012. As análises dos frutos e das sementes foram realizadas de novembro a dezembro de 2012 nos laboratórios de análise de sementes e de pós-colheita da Embrapa Hortaliças.

Utilizou-se a cultivar de pimenta BRS Mari (Capsicum baccatum var. pendulum) do tipo varietal dedo de moça (Carvalho et al., 2009). Para a produção de mudas, as sementes foram semeadas em bandejas de poliestireno expandido (isopor) com 128 células, contendo substrato comercial Bioplant ${ }^{\circledR}$. O transplante das mudas foi realizado aos 35 dias após semeadura. O solo foi preparado convencionalmente e as correções foram feitas de acordo com a análise química do mesmo.

No campo, as plantas foram dispostas em espaçamento de 1,2 m entre linhas x $0,8 \mathrm{~m}$ entre plantas. $\mathrm{O}$ cultivo das plantas seguiu as recomendações usuais para pimenta (Filgueira, 2005).

Os botões florais foram etiquetados no dia 15 de agosto, aproximadamente 105 dias após o transplantio das mudas. A colheita dos frutos foi realizada manualmente aos 20, 30, 40, 50, 60, 70 e 80 dias após a antese (DAA). Foram colhidos, ao acaso, 50 frutos de cada tratamento. Logo após a colheita, antes da extração de sementes, foi determinada a coloração e o comprimento dos frutos. Para determinação do teor de clorofila foi separado o pericarpo fresco e, para determinação do teor de capsaicina, no momento da extração, foram separados as sementes, a placenta e o pericarpo.

Após a extração, as sementes foram submetidas à secagem em temperatura ambiente por 24 horas, e após, secagem em estufa a $40^{\circ} \mathrm{C}$ por 24 horas, com a finalidade de atingir teor de água adequado para o armazenamento, de (aproximadamente 6\%, base úmida).
Em seguida, foram acondicionadas em embalagens impermeáveis e armazenadas em câmara fria a $15^{\circ} \mathrm{C}$ para posterior avaliação da qualidade fisiológica. Os testes e determinações realizados nos frutos constam a seguir.

Colorimetria de frutos (sistema $\mathbf{L} * \mathbf{a} * \mathbf{b}$ ) - A medida objetiva da coloração de pimentas foi realizada por meio de um sistema tri-axial ("tristimulus") de cores, que fornece três coordenadas $(\mathrm{L} * \mathrm{a} * \mathrm{~b} *)$, permitindo ao observador determinar com exatidão a coloração do objeto em estudo (Mattos et al., 2007). Neste sistema de representação de cor, os valores de $L^{*}, a^{*}$ e b* descrevem a uniformidade da cor no espaço tridimensional, em que o eixo x corresponde às cores que variam do verde $(-a)$ ao vermelho $(+a)$; o eixo y corresponde às cores que variam do amarelo (-b) ao $(+b)$ azul e o eixo $z$ corresponde às cores que variam do branco $(+\mathrm{L})$ ao preto $(-\mathrm{L})$. A avaliação da coloração foi realizada em dois pontos da superfície do fruto na região mediana; o colorímetro foi posicionado de modo a manter firme contato com a superfície do fruto, para ser efetuada a leitura. Os valores de $\mathrm{L}^{*}$, $a^{*}$ e b* foram anotados para posterior interpretação. As fórmulas utilizadas para interpretação foram ângulo Hue e Croma, de acordo com as seguintes equações:

$$
\begin{aligned}
& \text { 1- Ângulo Hue }=\operatorname{arcotang}(a, b) * \\
& 180 / \pi
\end{aligned}
$$

$$
\text { 2- Croma }=\left(a^{2}+b^{2}\right)^{1 / 2}
$$

Teor de clorofila no pericarpo - A determinação da clorofila total, a e b foi baseada na metodologia descrita por Inskeep \& Bloom (1985), citada por Mattos et al. (2007), com modificações realizadas no preparo da amostra. Pesaram-se $5 \mathrm{~g}$ da região mediana do pericarpo fresco e picado de cada tratamento, com três repetições, em balança digital com precisão de 0,0001 g. Em seguida, o material foi colocado em um almofariz e, dentro da capela, foram adicionados $10 \mathrm{~mL}$ do solvente N,N-dimetilformamida (DMF); com o auxílio de um pistilo, promoveu-se a maceração do material até obtenção de um macerado uniforme. Logo após, o material foi transferido para frascos, onde foram adicionados mais $10 \mathrm{~mL}$ de DMF. Os frascos foram tampados 
e protegidos com papel alumínio, para evitar a fotodegradação dos pigmentos clorofílicos, e armazenados em câmara fria a $5 \pm 2^{\circ} \mathrm{C}$ por 7 dias. Decorrido esse período, os frascos foram retirados da câmara fria e submetidos à agitação por $24 \mathrm{~h}$. O solvente foi filtrado em papel-filtro Whatmann $\mathrm{n}^{\circ} 4 \mathrm{e}$, em seguida, com auxílio do espectrofotômetro portátil (Chroma Meter CR-400), procedeu-se à leitura da absorbância, a 647 nm e 664,5 $\mathrm{nm}$. Os valores foram anotados para posterior interpretação dos resultados. A concentração de pigmentos $(\mathrm{mg} / \mathrm{kg})$ foi calculada de acordo com as seguintes equações:

Clorofila total $=17,95 * \mathrm{~A}_{647}+7,90 *$ $\mathrm{A}_{664,5}$

Clorofila $\mathrm{b}=20,47 * \mathrm{~A}_{647}-4,73 * \mathrm{~A}_{664,5}$ Clorofila $\mathrm{a}=12,70 * \mathrm{~A}_{664,5}-2,79 * \mathrm{~A}_{647}$

Comprimento dos frutos - Foram utilizados 10 frutos de cada tratamento e o comprimento dos mesmos foi mensurado em centímetros, com auxílio de um paquímetro digital. Cada fruto constituiu uma repetição.

Teor de capsaicina nos diferentes estádios fisiológicos dos frutos - A caracterização química foi realizada através do método AOAC Official Method 995.03, utilizado para determinação do teor de capsaicinóides entre 750 e 650.000 Unidades de Calor Scoville. Amostras de pericarpo, placenta e sementes dos frutos foram colocadas em estufa, com ventilação forçada de ar, para secagem durante três dias à temperatura de aproximadamente $60^{\circ} \mathrm{C}$. Posteriormente, as amostras foram moídas, quantificando-se o conteúdo de capsaicina de forma isolada para cada parte do fruto, conforme procedimento descrito a seguir. Preparo do padrão: Solução estoque - $150 \mathrm{mg}$ de $\mathrm{N}$-vanilila-n-nonamida foram colocados em um balão volumétrico de $100 \mathrm{~mL}$ e, em seguida, dissolvidos em álcool etílico grau cromatográfico até completar o volume do balão. Solução de trabalho - Foram transferidos $2 \mathrm{~mL}$ da solução estoque para um balão volumétrico de $100 \mathrm{~mL}$ e completado o volume com álcool etílico grau cromatográfico.

Preparo da amostra - As amostras secas foram trituradas em moinho e pesadas em alíquota de $2 \mathrm{~g} /$ tratamento, transferidas para um balão volumétrico de $100 \mathrm{~mL}$ ao qual foram adicionados $80 \mathrm{~mL}$ de etanol desnaturado. A solução foi agitada vigorosamente e colocada em banho-maria, a $70^{\circ} \mathrm{C}$, com agitação, por 5 horas. Ao final deste período, os balões foram retirados do banho-maria, resfriados até temperatura ambiente e o volume das soluções foi completado para $100 \mathrm{~mL}$. O sobrenadante foi mantido em refrigerador, a $4^{\circ} \mathrm{C}$, para posterior análise por cromatografia líquida de alta eficiência $\{$ High Performance Liquid Chromatography (HPLC) $\}$. Injeção da amostra - As amostras foram filtradas através de uma membrana FG (fluoropore) em PTFE 0,45 $\mu \mathrm{m}$ de poro, hidrofóbica, com auxílio de uma seringa de $5 \mathrm{~mL}$, coletando-se $2 \mathrm{~mL}$ do material filtrado, que foi transferido para frascos de vidro. Os frascos contendo as amostras foram colocados no compartimento de bandeja do cromatógrafo líquido de alta eficiência (HPLC). As condições do HPLC foram formadas por uma fase móvel composta por acetonitrila (40\%) e água contendo $1 \%$ de ácido acético $(60 \%)$, que atravessa uma fase estacionária formada pela coluna Luna C18(2), 150x4,6 mm, $5 \mu \mathrm{L}$ (marca Phenomenex) a um fluxo de $1,5 \mathrm{~mL}$ por minuto, resultando em um tempo total de corrida de 30 minutos para cada amostra. A separação dos capsaicinóides foi realizada pela injeção de $20 \mu \mathrm{L}$ de extrato de cada amostra em triplicatas, que percorreram a fase estacionária juntamente com a fase móvel. Injeção do padrão - Vinte $\mu \mathrm{L}$ da "solução de trabalho", previamente preparada e filtrada através de um filtro milipore $0,45 \mu \mathrm{m}$, foi injetada no HPLC, sendo a separação dos capsaicinóides realizada em uma coluna Luna C18(2), 150x4,6 mm, $5 \mu \mathrm{L}$ (marca Phenomenex) a um fluxo de 1,5 mL por minuto. Detecção de capsaicinóides - Os picos de capsaicinóides foram obtidos a partir de um detector do tipo fotodiodo (PDA-“photodiodearray detector") UV-vis (ultravioleta - visível), utilizando-se como referência o comprimento de onda de $280 \mathrm{~nm}$. A identificação dos capsaicinóides foi baseada na comparação do tempo de retenção dos picos relativos aos capsaicinóides encontrados em amostras de padrões comerciais de capsaicina e diidrocapsaicina. A quanti- ficação dos capsaicinóides foi realizada a partir da comparação da área do pico obtida após injeção do padrão de capsaicina na concentração de $0,015 \mathrm{mg}$ / $\mathrm{mL}$ com as áreas obtidas após injeção das amostras. Uma nova alíquota do padrão foi injetada a cada seis amostras analisadas. Os resultados foram expressos em SHU ('Scoville Heat Units') de nordiidrocapsaicina, capsaicina e diidrocapsaicina e capsaicinóides totais. As seguintes equações foram utilizadas para o cálculo:

$\mathrm{SHU}_{\mathrm{N}}=\left(\mathrm{M}_{\mathrm{N}} / \mathrm{M}_{\mathrm{S}}\right)\left(\mathrm{C}_{\mathrm{S}} \times \mathrm{P}_{\mathrm{S}} / \mathrm{W}_{\mathrm{T}}\right) *$ $(100 / 0,98) *(9300)$

$\mathrm{SHU}_{\mathrm{C}}=\left(\mathrm{M}_{\mathrm{C}} / \mathrm{M}_{\mathrm{S}}\right)\left(\mathrm{C}_{\mathrm{S}} \times \mathrm{P}_{\mathrm{S}} / \mathrm{W}_{\mathrm{T}}\right) *$ $(100 / 0,89) *(16100)$

$\mathrm{SHU}_{\mathrm{D}}=\left(\mathrm{M}_{\mathrm{D}} / \mathrm{M}_{\mathrm{S}}\right)\left(\mathrm{C}_{\mathrm{S}} \times \mathrm{P}_{\mathrm{S}} / \mathrm{W}_{\mathrm{T}}\right) *$ $(100 / 0,93) *(16100)$

$\mathrm{SHU}_{\mathrm{T}}=\mathrm{SHU}_{\mathrm{N}}+\mathrm{SHU}_{\mathrm{C}}+\mathrm{SHU}_{\mathrm{D}}$ emque, $\mathrm{SHU}_{\mathrm{N}}, \mathrm{SHU}_{\mathrm{C}}, \mathrm{SHU}_{\mathrm{D}}, \mathrm{SHU}_{\mathrm{T}}=\mathrm{SHU}$ dos capsaicinóides nordiidrocapsaicina, capsaicina, diidrocapsaicina e totais, respectivamente; $\mathrm{M}_{\mathrm{N}}, \mathrm{M}_{\mathrm{C}}, \mathrm{M}_{\mathrm{D}}, \mathrm{M}_{\mathrm{S}}$ = média das áreas dos picos de nordiidrocapsaicina, capsaicina, diidrocapsaicina e do padrão, respectivamente; $\mathrm{C}_{\mathrm{S}}=$ concentração do padrão de capsaicina em $\mathrm{mg} / \mathrm{mL}$; $\mathrm{Ps}=$ área do pico relativo ao padrão de capsaicina; $\mathrm{Wt}=$ peso da amostra teste.

Os testes e determinações nas sementes constam a seguir.

Teor de água - Foi avaliado em estufa a $105 \pm 3^{\circ} \mathrm{C}$ durante 24 horas, utilizando-se duas sub-amostras para cada tratamento, de acordo com as Regras para Análise de Sementes (RAS) (Brasil, 2009). Os resultados foram expressos em porcentagem média por tratamento. Massa de 100 sementes A massa média foi determinada com quatro repetições de 100 sementes que foram pesadas em balança digital com precisão de $0,001 \mathrm{~g}$, sendo os cálculos efetuados conforme recomendações das RAS (Brasil, 2009) e os resultados expressos em gramas (g). Germinação - Cada tratamento foi representado por quatro repetições de 50 sementes distribuídas sobre duas folhas de papel mata borrão, umedecidas com água na proporção de 2,5 vezes a massa do substrato seco, em caixas plásticas tipo "gerbox". As caixas foram mantidas em germinadores sob regime alternado de 
temperatura e luz $20^{\circ} \mathrm{C}$ (durante $16 \mathrm{~h}$, correspondente ao período noturno) e $30^{\circ} \mathrm{C}$ (durante $8 \mathrm{~h}$, correspondente ao período diurno). As avaliações foram realizadas no décimo quarto (primeira contagem) e no vigésimo primeiro dias após a semeadura e os resultados foram expressos em porcentagem de plântulas normais, conforme critérios estabelecidos pelas Regras para Análise de Sementes (Brasil, 2009). Emergência de plântulas em casa de vegetação - As sementes foram distribuídas em bandejas multicelulares de poliestireno expandido contendo 200 células preenchidas com substrato comercial Bioplant ${ }^{\circledR}$. As bandejas foram mantidas em casa de vegetação. Cada tratamento foi composto por quatro repetições de 50 sementes. As avaliações foram realizadas no décimo quarto e vigésimo primeiro dias após a instalação do teste, computando-se a porcentagem de plântulas normais. Envelhecimento acelerado - Foram utilizadas caixas de plástico $(11 \times 11 \mathrm{~cm})$, funcionando como compartimentos individuais, possuindo em seu interior uma bandeja com tela de alumínio, onde foram distribuídas em camadas uniformes 200 sementes por tratamento em quatro repetições de 50 sementes. Dentro de cada compartimento individual, foram adicionados $45 \mathrm{~mL}$ de solução saturada de $\mathrm{NaCl}$ (40 $\mathrm{g}$ de $\mathrm{NaCl} / 100 \mathrm{~mL}$ de água). As caixas contendo as sementes foram fechadas e mantidas em uma câmara de envelhecimento acelerado, regulada a temperatura constante de $41^{\circ} \mathrm{C}$ por 48 horas. Decorrido o período de envelhecimento, as sementes foram submetidas ao teste de germinação conforme metodologia descrita anteriormente. A avaliação foi realizada aos 21 dias após a instalação do teste. Os resultados foram expressos em porcentagem média de plântulas normais para cada tratamento.

Utilizou-se o delineamento inteiramente casualizado, com quatro repetições, exceto para a coloração dos frutos, onde foram utilizadas 10 repetições, e para a determinação dos teores de clorofila e capsaicina, que empregou três repetições. Os dados foram submetidos à análise de regressão pelo procedimento PROC REG do programa computacional SAS.

\section{RESULTADOS E DISCUSSÃO}

No teste de coloração $\mathrm{L}^{*} \mathrm{a}^{*} \mathrm{~b}^{*}$, os valores referentes à luminosidade $\mathrm{L}^{*}$ para os frutos colhidos aos 80 DAA houve decréscimo de $51,3 \%$, quando comparados com os valores de $\mathrm{L}^{*}$ para frutos colhidos aos 20 DAA (Figura 1A). Esses valores descrevem que o fruto imaturo possuía maior brilho em relação aos frutos maduros. Os valores de a* apresentaram aumento considerável durante todo o desenvolvimento, variando de -18,31 em frutos colhidos aos 20 DAA até 37,75 em frutos colhidos aos 80 DAA, indicando a mudança de coloração do verde brilhante para o vermelho opaco. Os valores de $b^{*}$ em todas as etapas de maturação foram decrescentes, ou seja, reduziram-se de 45,94 para 20,0, em frutos colhidos aos 20 e 80 DAA, respectivamente. Os valores de $L^{*}$ de 60,21 e a* de $-18,31$, encontrados nos frutos colhidos aos 20 DAA, indicam maior preservação da cor verde devido à maior concentração de clorofila (Figura 1B). A coloração dos frutos de pimenta em cada estádio de maturação depende da capacidade dos frutos de sintetizar carotenóides e até mesmo de reter pigmentos de clorofila (Hornero-Méndez \& Mínguez-Mosquera, 2002).

Foram observadas diferenças significativas no teor de clorofila em todos os estádios de maturação, sendo que a partir de 60 DAA, o teor estabilizou-se (Figura 1B). O estádio de maturação que apresentou o maior teor de clorofila foi aos 20 DAA. Isso se deve à imaturidade dos frutos, ainda com maior predominância de cloroplastos (Hornero-Méndez \& Mínguez-Mosquera, 2002); a molécula de clorofila presente nos cloroplastos absorve a energia radiante e ativa o sistema fotossintético. Já a partir de 70 DAA, o teor de clorofila foi mínimo, evidenciando o processo avançado de amadurecimento.

Os resultados obtidos para o comprimento dos frutos apresentaram boa estratificação, demonstrando aumento gradativo até os 50 DAA. A partir desse momento, houve leve tendência à diminuição do comprimento dos mesmos
(Figura 1C). Isso pode ser atribuído ao fato de se tratar de uma espécie de crescimento indeterminado, onde o tamanho dos frutos tende a diminuir com o aumento da ordem de frutificação na planta (Dias et al., 2006).

A análise de variância da regressão não demonstrou tendência significativa no teor dos capsaicinóides no pericarpo, indicando que não houve diferenças significativas desses capsaicinóides ao longo do processo de maturação dos frutos. As concentrações dos capsaicinóides, capsaicina e diidrocapsaicina encontrados no pericarpo apresentaram a mesma tendência. Os picos mais altos dos capsaicinóides foram observados aos 70 DAA. Os teores de capsaicina e diidrocapsaicina apresentaram variação de $3.552,24$ a $16.595,68$ mg/g e $1.443,14$ a $7.947,45 \mathrm{mg} / \mathrm{g}$, respectivamente (Figura 1D). O teor de capsaicina total, correspondente à soma dos dois capsaicinóides, variou de 4.995 a $24.543 \mathrm{mg} / \mathrm{g}$. A nordiidrocapsaicina não foi detectada no pericarpo do fruto em nenhum estádio de maturação.

Quanto maior o grau de maturação da pimenta, maior o conteúdo de capsaicina. Dessa forma, o conteúdo de capsaicina nos frutos pode estar relacionado com a cor dos frutos e, consequentemente, com o grau de maturação (Long-Solis, 1998).

$\mathrm{Na}$ placenta, local dos frutos onde a concentração de capsaicina é maior, foram detectados os picos mais altos de capsaicina $(296.015,5 \mathrm{mg} / \mathrm{g})$, e menores quantidades de diidrocapsaicina (148.932,8 mg/g) e nordiidrocapsaicina $(3.288,93 \mathrm{mg} / \mathrm{g})$. A pungência total não apresentou diferenças após 40 DAA, sendo a média ajustada pela regressão cúbica em 422.044,6 mg/g (Figura 1E).

Entre os princípios pungentes, $90 \%$ deles estão localizados na placenta dos frutos. Já as sementes não são fonte da pungência, mas, ocasionalmente, podem absorver capsaicina devido à proximidade com a placenta. O valor SHU pode variar de zero (pimentões e pimentas doces) a mais de 300 mil (pimentas muito picantes), conforme a espécie. Esse valor pode ser influenciado por vários fatores, tais como temperatura, adubação e irrigação (Ribeiro \& Reifschneider, 2008). 


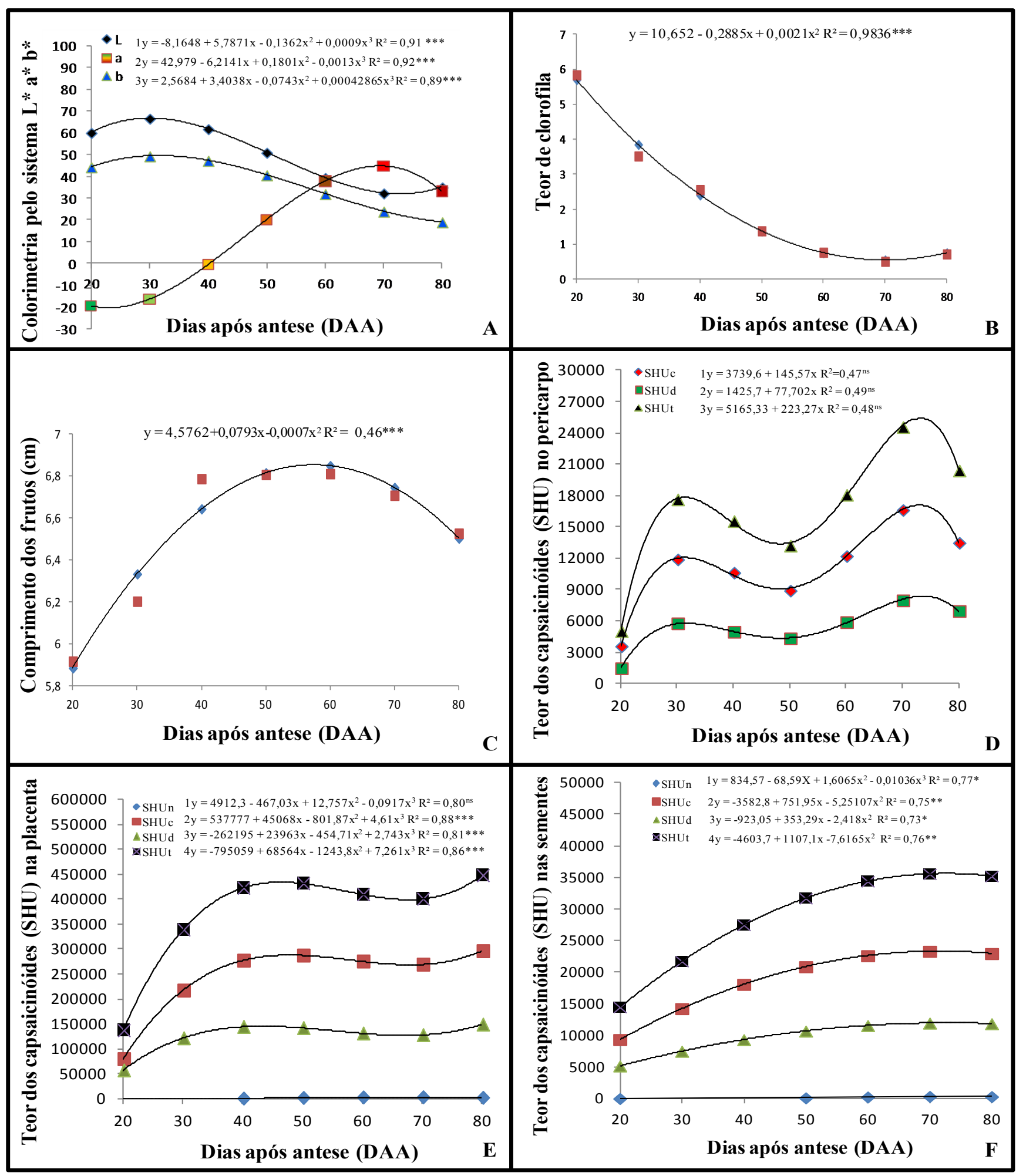

Figura 1. Colorimetria pelo sistema $\mathrm{L}^{*} \mathrm{a} \mathrm{b}^{*}(\mathrm{~A})$, teor de clorofila (B), comprimento longitudinal (C), teor dos capsaicinpóides (SHU) no pericarpo (D), teor dos capsaicinóides (SHU) na placenta (E) e teor dos capsaicinóides (SHU) nas sementes (F) dos frutos de pimenta cv. BRS Mari em função do estádio de maturação dos frutos. SHUn= nordiidrocapsaicina; $\mathrm{SHUc}=$ capsaicina; $\mathrm{SHUd}=\mathrm{diidrocapsaicina;} \mathrm{SHUt}=$ total. Pontos $(\diamond)$ e ( $(\square)$ representam dados estimados e observados, respectivamente. ns= não significativo $(\alpha>0,05)$; *significativo a $5 \%$ $(\alpha \leq 0,05)$; **significativo a $1 \%(\alpha \leq 0,01) ; * *$ significativo a $0,1 \%(\alpha \leq 0,001)$ \{Colorimetry by the L*a*b* (A) system, chlorophyll content (B), longitudinal length (C) capsaicinpoid content (SHU) in the pericarp (D) capsaicinoid content (SHU) in the placenta (E) and capsaicinoid content (HUS) in the seeds (F) of pepper fruits cv. BRS Mari depending on the maturation stage. SHUn= nordihydrocapsaicina; SHUc= capsaicin, SHUd= dihydrocapsaicin; SHUt $=$ total. The marks $(\diamond)$ and $(\square)$ are estimated and observed data, respectively. ns $=$ not significant $(\alpha>0.05)$, *significant at 5\% ( $\alpha \leq 0.05) ; * *$ significant at $1 \%(\alpha \leq 0.01) ; * * *$ significant at $0.1 \%(\alpha \leq 0.001)\}$. Brasília, Embrapa Hortaliças, 2012. 


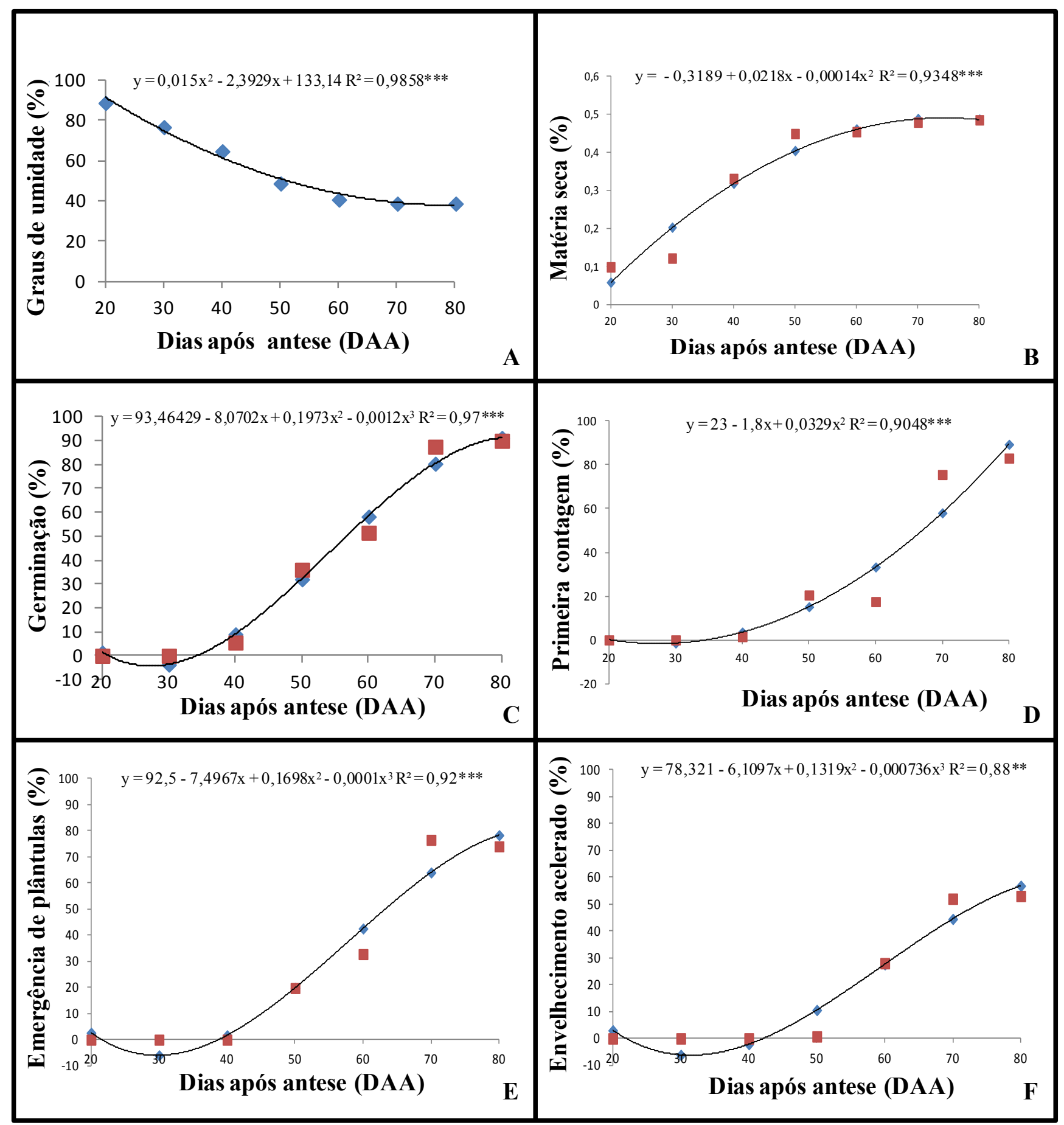

Figura 2. Graus de umidade (A), massa seca (B), germinação (C), primeira contagem de germinação (D), emergência de plântulas (E) e envelhecimento acelerado (F) em sementes de pimenta cv. BRS Mari em função do estádio de maturação dos frutos. Pontos ( $)$ e ( $₫$ ) representam dados estimados e observados, respectivamente. $* *$ significativo a $1 \%(\alpha \leq 0,01) ; * * *$ significativo a $0,1 \%(\alpha \leq 0,001)\{$ seed moisture (A), dry weight (B), germination (C), first count (D), seedling emergence (E) and accelerated aging (F) in seeds of pepper cv. BRS Mari depending on the stage of maturation. The marks $(*)$ and $(\square)$ are estimated and observed data, respectively. $* *$ Significant at $1 \%(\alpha \leq 0.01)$; ***significant at $0.1 \%(\alpha \leq 0.001)\}$. Brasília, Embrapa Hortaliças, 2012.

No presente estudo, os teores de capsaicina detectados nas diferentes partes do fruto estão acima dos resultados encontrados por outros autores, que obtiveram, para 63 acessos de $C$. chinense, variação na concentração de capsaicina de 0,01 a 1,52 mg/g de fruto fresco (Antonious et al., 2009). Entretanto, os valores de capsaicina encontrados nessa pesquisa não podem ser comparados com a maioria dos outros trabalhos, uma vez que a quantificação foi realizada em partes separadas do fruto, e não em todo o fruto como de rotina. A elevada pungência de 'BRS Mari', confirmada pelo alto conteúdo de capsaicina obtido, em especial na placenta, foi um resultado altamente 
significativo e promissor, especialmente para a indústria farmacêutica, que já utiliza a capsaicina como princípio ativo para a produção de diversos fármacos, e para as agroindústrias de processamento de molhos líquidos ou desidratados em flocos com as sementes observados na 'pimenta calabresa'.

Nas sementes, o conteúdo da nordiidrocapsaicina somente foi detectado a partir de 50 DAA, porém com concentrações muito baixas, isto é, 266,97 $\mathrm{mg} / \mathrm{g}$ em média. Com relação aos teores de capsaicina, a tendência foi crescente conforme o processo de maturação dos frutos; no entanto, aos 80 DAA, apresentou leve declínio. $O$ pico máximo de $23.323,6 \mathrm{mg} / \mathrm{g}$, pela regressão quadrática, foi observado aos 70 DAA. Para a pungência total, foi observada tendência crescente até os 70 DAA e, aos 80 DAA, apresentou leve decréscimo (Figura 1F). O estádio de desenvolvimento dos frutos interfere no conteúdo de capsaicinóides, observando-se acúmulo até o início do amadurecimento e decréscimo a partir desse estádio (Bosland \&Votava, 1999).

Os teores da nordiidrocapsaicina, capsaicina e diidrocapsaicina obtidos no pericarpo, placenta e sementes apresentaram diferenças altamente significativas. Os picos mais altos foram observados na placenta $(447.252,0 \mathrm{mg} / \mathrm{g})$, seguidos das sementes $(35.572,23 \mathrm{mg} / \mathrm{g})$ e, finalmente, do pericarpo $(23.026,08$ $\mathrm{mg} / \mathrm{g})$.

A diversidade de valores encontrados para os capsaicinóides é esclarecida por alguns autores como uma resposta influenciada pela interação genótipo-ambiente, algumas vezes com predomínio dos fatores ambientais e manejo da cultura. A mesma cultivar de pimenta plantada em diferentes locais apresenta diferentes teores de capsaicinóides, pois qualquer estresse à planta pode alterar a pungência do fruto (Bosland \& Votava, 1999; Ribeiro \& Reifschneider, 2008; Borges-Goméz et al., 2010).

Segundo a regressão quadrática, o grau de umidade das sementes decresceu com o avanço do processo de maturação, sendo que, aos 20 DAA, as sementes encontravam-se totalmente imaturas, com o teor de água de $89 \%$. A partir daí, os teores de água apresentaram tendência decrescente até os 70 DAA, quando as sementes apresentaram teor de água mínimo, ou seja, 39\%, momento em que a semente pode ter atingido a maturidade fisiológica; a partir deste ponto, observou-se estabilização no grau de umidade (Figura 2A). Embora tenha ocorrido redução gradativa do teor de água das sementes ao longo do seu desenvolvimento, o valor encontrado ao final do processo ainda é considerado relativamente alto (39\%), o que também foi descrito por outros autores para sementes de frutos carnosos (Demir \& Ellis, 1992a,b; Demir et al., 2002; Dias et al., 2006). Em espécies de frutos carnosos como é o caso da pimenta, ocorre equilíbrio osmótico entre o pericarpo do fruto, rico em solutos, e as sementes, resultando na estabilização do teor de água destas ao final da maturação (Barbedo et al., 1994). Embora seja utilizado por alguns autores, o teor de água das sementes não é um indicador adequado de maturidade fisiológica, por sofrer influências ambientais e genéticas.

A massa de 100 sementes, apresentou rápido e constante aumento ao longo da maturação dos frutos, estabilizando-se a partir de 60 DAA (Figura 2B). Esse comportamento indica que pode ter cessado a translocação de assimilados, ou seja, rompimento da conexão vascular da planta mãe para a semente. Essa característica tem sido apontada por outros autores como um indicativo do ponto de maturidade fisiológica, partindo-se do princípio de que a ligação entre a semente e a planta mãe foi interrompida (Demir \& Ellis, 1992a; Carvalho \& Nakagawa, 2000).

Foi observada tendência de aumento gradativo da germinação nos diferentes estádios de maturação. Notadamente, os valores máximos de germinação ocorreram aos 70 e 80 DAA. Aos 70 DAA, a germinação estava acima de $80 \%$, coincidindo com o valor máximo de matéria seca $(0,478 \mathrm{~g})$. Vale ressaltar que nos dois primeiros estádios de maturação, aos 20 e 30 DAA, a germinação foi nula (Figura 2C).

Estudos relacionados com maturidade fisiológica de sementes têm apresentado resultados contraditórios quanto à ocorrência da qualidade máxima da semente durante o desenvolvimento. Em sementes de pimentão (C. annuum), foi verificado que o ponto de maturidade fisiológica ocorreu a partir dos 55 dias após a antese, período em que foram observados também valores máximos de vigor, massa seca e germinação das sementes (Gonçalves, 1997). A qualidade máxima das sementes de tomate ocorreu mais de 20 dias após o máximo acúmulo de matéria seca (Demir \& Ellis, 1992a). Resultados semelhantes foram verificados em outras solanáceas, como por exemplo em sementes de berinjela (Demir et al., 2002) e de pimentão (Demir \& Ellis, 1992b). Por outro lado, porcentagens mais altas de germinação de sementes de tomate foram obtidas antes do máximo acúmulo de matéria seca (Dias et al., 2006).

No presente trabalho, nas fases mais avançadas de maturação, ou seja, aos 70 e 80 DAA, foram obtidos o máximo vigor nos diferentes parâmetros (Figuras $2 \mathrm{D}, 2 \mathrm{E}, 2 \mathrm{~F})$. Baixas porcentagens de germinação e vigor de sementes oriundas de frutos colhidos aos 20 DAA e em estádios iniciais de maturação como aos 30, 40 e 50 DAA devem-se à imaturidade fisiológica das sementes (Figura 2D). Adiciona-se a isso a possibilidade de ocorrência de dormência das sementes nesses estádios iniciais, o que afeta diretamente seu real potencial de germinação e vigor.

Os resultados obtidos para a emergência das plântulas em casa de vegetação apresentaram tendência crescente ao longo do processo de maturação, sendo que os valores máximos foram observados em estádios mais avançados de maturação, ou seja, aos 70 e 80 DAA. Por outro lado, piores desempenhos foram observados nas sementes provenientes de frutos colhidos em estádios iniciais de maturação (Figura 2E).

Os dados obtidos no teste de envelhecimento acelerado mostraram que o máximo vigor foi obtido aos 70 DAA, coincidindo com os resultados dos testes de emergência de plântulas em casa de vegetação e de germinação (Figura $2 \mathrm{~F}$ ). $\mathrm{O}$ teste de envelhecimento acelerado tem como base o fato de que a taxa de deterioração das sementes é aumentada consideravelmente pela sua exposição à temperatura e umidade relativa elevadas, sendo estes os fatores ambientais mais relacionados à deterioração 
das sementes (Marcos Filho, 1999). O teste com o uso de solução saturada de $\mathrm{NaCl}$ demonstrou-se eficiente para detectar níveis de qualidade fisiológica em sementes de pimenta-malagueta, $C$. frutescens (Torres, 2005).

Com base nos resultados obtidos neste trabalho, a máxima qualidade fisiológica (germinação e vigor) das sementes de pimenta 'BRS Mari' ocorreu em frutos com idade entre 70 e 80 DAA, coincidindo com o máximo acúmulo de matéria seca. De modo geral, o vigor das sementes aumentou gradativamente ao longo do processo de maturação.

Por ser uma espécie de crescimento indeterminado, com florescimento contínuo, apresentando frutos em diferentes estádios de maturação, há certa dificuldade, em nível de campo, para determinação da melhor época para a colheita dos frutos, visando à obtenção de bom rendimento de sementes e alta qualidade fisiológica. Como os frutos das diferentes espécies de pimenta são carnosos, o processo de maturação das sementes continua mesmo após a colheita dos frutos. Assim, o emprego adequado de técnicas de repouso ou armazenamento pós-colheita dos frutos, antes da extração das sementes, permite que as sementes ainda não totalmente maduras completem sua maturação dentro dos frutos, enquanto as já maduras terão sua qualidade preservada por se manterem em equilíbrio osmótico dentro do fruto, ou seja, com alto grau de umidade (Barbedo et al., 1994).

Em síntese, a maturidade fisiológica de sementes de pimenta $C$. baccatum var. pendulum 'BRS Mari' ocorreu aos 70 dias após a antese. Neste estádio, foram observados valores máximos de germinação, vigor e matéria seca das sementes. Além disso, foram observados neste estádio os picos mais altos de capsaicina, coincidindo com o momento em que os frutos apresentavam coloração vermelha e teores mínimos de clorofila.

\section{REFERÊNCIAS}

ANTONIOUS GF; BERKE T; JARRET RL. 2009. Pungency in Capsicum chinense: variation among countries of origin. Journal of Environmental Science and Health 44: 179-184.

BARBEDO ASC; ZANIN ACW; BARBEDO CJ; NAKAGAWA J. 1994. Efeitos da idade e do período de repouso pós-colheita dos frutos sobre a qualidade de sementes de berinjela. Horticultura Brasileira 12: 14-18.

BORGES-GOMEZ L; CÁRDENAS LC; NOVELO JR; FREGOSO MS; OREGEL VR; COUOH EV. 2010. Capsaicinoides en chile habanero (Capsicum chinense) bajo diferentes condiciones de humedad y nutrición. Terra Latino Americana 28: 35-41.

BOSLAND, PW; VOTAVA EJ. 1999. Peppers: vegetable and spice Capsicums. New York: CAB Publishing. p. 66-83.

BRASIL. Ministério da Agricultura, Pecuária e Abastecimento. 2009. Regras para análise de sementes. Secretaria de Defesa Agropecuária. Brasília: Mapa/ACS. 395p.

CARVALHO NM; NAKAGAWA J. 2000. Sementes: ciência, tecnologia e produção. 4 ed. Jaboticabal: Funep. 588p.

CARVALHO SIC; RIBEIRO CSC; HENZ GP; REIFSCHNEIDER FJB. 2009. 'BRS Mari': Nova cultivar de pimenta dedo-de-moça para processamento. Horticultura Brasileira 27: 571-573.

DEMIR I; ELLIS RH. 1992a. Changes in seed quality during seed development and maturation in tomato. Seed Science Research 2: 81-87.

DEMIR I; ELLIS RH. 1992b. Development of pepper (Capsicum annuum) seed quality. Annals of Applied Biology 121: 385-399.

DEMIR I; MAVI K; SERMENLI T; OZCOBAN M. 2002. Seed development and maturation in aubergine (Solanum melongena) Gartenbauwissenschaft 67: 148-154.

DIAS DCFS; RIBEIRO FP; DIAS LAS; SILVA DJH; VIDIGAL DS. 2006. Tomato seed quality in relation to fruit maturation and post- harvest storage. Seed Science and Technology 34: 691-699.

FILGUEIRA FAR. 2005. Novo Manual de Olericultura: Agrotecnologia moderna na produção e comercialização de hortaliças. 2 ed. Viçosa : UFV. 412p.

FREITASRA; NASCIMENTOWM; CARVALHO SIC. 2008. Produção de sementes. In: RIBEIRO CSC; LOPES CA; CARVALHO SIC; HENZ GP; REIFSCHNEIDER FJB (eds). Pimentas Capsicum. Brasília: Embrapa Hortaliças. p.173-187.

GONÇALVES CP. 1997. Desenvolvimento e maturação fisiológica da semente de pimentão cv. All Big. Areia: UFPB. 90p (Dissertação mestrado).

HORNERO-MÉNDEZ D; MÍNGUEZMOSQUERA MI. 2002. Chlorophyll disappearance and chlorophyllase activity during ripening of Capsicum annum fruits. Journal of Food Science and Agriculture 82: 1564-1570.

LONG-SOLIS. 1998. Capsicum y cultura: la historia del chilli. México: Ed. Fundo de Cultura Econômica. p.240.

MARCOS FILHO, J. 1999. Testes de vigor: importância e utilização. In: KRZYZANOWSKI FC; VIEIRA RD; FRANÇA NETO JB. Vigor de sementes: conceitos e testes. Londrina: ABRATES. p.1-24.

MATTOS LM; MORETTI CL; HENZ GP. 2007. Protocolos de avaliação da qualidade química e física de pimentas (Capsicum sp.). Brasília: Embrapa Hortaliças. 9p. (Comunicado Técnico, n.50).

NASCIMENTO WM. 2004. Mercado de sementes de pimentas no Brasil. In: ENCONTRO NACIONAL DO AGRONEGÓCIO PIMENTAS (Capsicum sp.), 1. Anais... Brasília: Embrapa Hortaliças: (CD-ROM).

NASCIMENTO WM; DIAS DCFS; FREITAS RA. 2006. Produção de sementes de pimentas: cultivo da pimenta. Informe Agropecuário 27: 235.

RIBEIRO CSC; REIFSCHNEIDER FJB. 2008. Genética e melhoramento. In: RIBEIRO CSC; LOPES CA; CARVALHO SIC; HENZ GP; REIFSCHNEIDER FJB (eds). Pimentas Capsicum. Brasília: Embrapa Hortaliças. p.55-70,

TORRES SB. 2005. Envelhecimento acelerado em sementes de pimenta-malagueta (Capsicum frutescens). Revista Ciência Agronômica 36: 98-104 